\title{
Growth Hormone Treatment Adherence in Prepubertal and Pubertal Children with Different Growth Disorders
}

\author{
Klaus Hartmann ${ }^{a} \quad J$ Jochen Ittner ${ }^{b}$ Elke Müller-Rossberg ${ }^{c}$ Eckhard Schönau $^{d}$ \\ Roger Stephan ${ }^{\mathrm{e}}$ K.-Peter Ullrich ${ }^{f}$ Bernd Hoppe $^{g}$ Rene Ramseger ${ }^{\mathrm{h}}$ \\ Jürgen Brämswig ${ }^{\mathrm{i}}$ \\ ${ }^{a}$ Medical Centre of Childhood and Adolescence, Frankfurt, ${ }^{b}$ Endokrinologische Praxis, Augsburg, ${ }^{C}$ Klinikum Esslingen, \\ Esslingen, ${ }^{d}$ Universität Zu Köln, Köln, ${ }^{e}$ Kinderärztliche Praxis Dres., Hildesheim, ${ }^{\mathrm{f}} \mathrm{FZMB}$, Bad Langensalza, ${ }^{9}$ Division of \\ Paediatric Nephrology, Department of Paediatrics, University of Bonn, Bonn, ${ }^{\mathrm{h}}$ Merck Serono GmbH, Darmstadt, and \\ 'Universitäts-Kinderklinik, Münster, Germany
}

\section{Key Words}

Growth hormone treatment - Recombinant human growth hormone - Compliance - Children and adolescents . easypod ${ }^{\mathrm{TM}} \cdot$ Saizen $^{\circledR}$. Adherence

\begin{abstract}
Background/Aims: Treatment of children with growth disorders with recombinant human growth hormone is necessary for improved outcomes, including final height. Methods: Adherence data from the Observational Study Saizen ${ }^{\circledR}$ _ online, recorded with the easypod ${ }^{\mathrm{TM}}$ device collected between October 2009 and May 2011, were analyzed in pediatric patients receiving recombinant human growth hormone treatment for a variety of growth disorders. Results: Data from 75 children ( 46 boys, 29 girls) with different growth disorders were analyzed over a period of $343 \pm 201$ (SD) days. Boys and girls showed similar mean \pm SD adherence rates of $90.5 \pm 3.1 \%$ and $92.2 \pm 10.7 \%$, respectively. Pubertal children $(n=41)$ had a significantly lower adherence rate $(89.1 \pm$ $13.7 \%)$ than prepubertal children $(n=29)(96.5 \pm 3.9 \%$; $p<$ 0.005). There were nonsignificant differences in adherence
\end{abstract}

\begin{tabular}{ll}
\hline KARGER & $\begin{array}{l}\text { (c) 2013 S. Karger AG, Basel } \\
1663-2818 / 13 / 0801-0001 \$ 38.00 / 0\end{array}$ \\
$\begin{array}{l}\text { E-Mail karger@karger.com } \\
\text { www.karger.com/hrp }\end{array}$ & $\begin{array}{l}\text { This is an Open Access article licensed under the terms of the } \\
\text { Creative Commons Attribution-NonCommercial 3.0 Un- } \\
\text { ported license (CC BY-NC) (www.karger.com/OA-license), } \\
\text { applicable to the online version of the article only. Distribu- } \\
\text { tion permitted for non-commercial purposes only. }\end{array}$
\end{tabular}

rates according to diagnosis: growth hormone deficiency $(n=48) 91.4 \pm 11.0 \%$, small for gestational age $(n=18) 91.1 \pm$ $15.3 \%$, Turner syndrome $(n=6) 86.0 \pm 14.5 \%$, and chronic renal failure $(n=3) 99.3 \pm 1.0 \%$, although the latter two groups were small. Conclusion: Our data indicate that only a small number of pediatric patients using the easypod device had poor adherence to treatment. Further reliable adherence data are required to identify factors affecting longterm adherence in this population.

Copyright $\odot 2013$ S. Karger AG, Basel

\section{Introduction}

Human growth hormone ( $\mathrm{hGH}$ ), somatotropin, is a polypeptide hormone consisting of 191 amino acids produced by the pituitary gland. hGH is essential in the growth and maturation process of children and is also physiologically important in adults [1].

Pituitary-derived hGH has been used since the 1950s [2]. With the availability of recombinant hGH (rhGH) from $1985[3,4]$, it has become possible to treat greater

Dr. Klaus Hartmann

Medizinisches Kinder und Jugendzentrum für Endokrinologie und Diabetologie Lyoner Strasse 54

DE-60528 Frankfurt (Germany)

E-Mail hartmann@medikijz.de 
numbers of patients for a wider range of growth disorders. rhGH is used to treat growth hormone deficiency (GHD) in children and adults, and to promote growth in children with Turner syndrome (TS), chronic renal failure (CRF) and idiopathic short stature, and children born small for gestational age (SGA) who fail to demonstrate catch-up growth [5].

There are few published studies relating adherence with rhGH treatment to clinical outcome (final height) in GHD [6-9]; but to achieve an optimal growth response during rhGH therapy, it is important that children adhere to the prescribed GH dose [10-12]. Maintaining adherence to rhGH treatment is difficult as the short-term burden of daily injection administration is often more apparent than the long-term benefits of therapy. Furthermore, assessing adherence is difficult and few reliable data exist on the adherence rate of this cost-intensive treatment. Differences in adherence rates observed between studies may in part be linked to the different methods used to quantify adherence. Cutfield et al. [9] calculated the prescribed versus consumed dose in a cohort of 150 patients and observed that $66 \%$ of patients were less than $85 \%$ adherent over a 4 -month period, and these patients were defined as noncompliant.

In 2007, an electronic autoinjector device (easypod ${ }^{\mathrm{TM}}$, Merck Serono S.A., Geneva, Switzerland) was introduced for the administration of rhGH (Saizen ${ }^{\circledR}$, Merck Serono S.A.) $[13,14]$. easypod is a hidden-needle autoinjector device that records the date and time of injection, prescribed dose (mg), injected dose (mg) and injection status (dose setting, performed, missed or partial injection). Owing to the electronic registration of each rhGH injection, patient adherence can be monitored accurately [14]. The device has been well accepted by patients, with $98 \%$ of survey respondents in one study reporting a 'good' or 'very good' overall impression of this device [13], and $90 \%$ of children in another study wanting to continue using the device [15].

The electronic Observational Study (OS) Saizen ${ }^{\circledR}$ online is an observational study to evaluate the long-term efficacy of Saizen in adult and pediatric patients. Here we report data from pediatric patients administering rhGH with the easypod device in order to evaluate rhGH therapy adherence in children and adolescents with different growth disorders.

\section{Methods}

OS Saizen-online is a prospective, multicenter, open-label, noninterventional study evaluating rhGH therapy in pediatric patients with GHD, TS or CRF, those born SGA and adults with severe
GHD. The primary aim of this observational study is to collect long-term efficacy data for rhGH therapy in routine clinical use, in patients for periods of up to 15 years. Patients already receiving Saizen (somatotropin for injection, Merck Serono S.A.) or in whom the clinical decision had already been made to initiate Saizen treatment were eligible for inclusion. Patient recruitment began in 2007 and is planned to continue until 2016, with the study ending in 2031. Yearly interim analyses are planned, with the final analysis conducted at study completion in 2031. This paper reports on a secondary endpoint: the collection of pediatric adherence data.

This study was performed in accordance with sections 4 (23) and 67 (6) of the German Medicines Act and notified to the appropriate German federal authorities [16].

\section{Data Collection}

Adherence data were collected from pediatric patients receiving rhGH therapy using the easypod administration device in conjunction with the clinical kit software. The easypod data from individual patients attending 11 pediatric endocrinology centers in Germany from October 2009 to May 2011 were uploaded to the internet-based Saizen electronic data capture system (SAIZENEDC). In addition, data on demographics, medical history, height $(\mathrm{cm})$ and growth velocity $(\mathrm{GV}, \mathrm{cm} /$ year) were extracted from the SAIZEN-EDC database.

Data sets with dates prior to 2009 (prior to the introduction of easypod clinical kit software), data with more than one injection per day (unless verified), and erroneously prescribed doses of $0 \mathrm{mg}$ and incomplete data sets were excluded from this evaluation. Adherence was assessed with respect to the proportion of actual injected $\mathrm{rhGH}$ per patient as recorded by easypod compared with the prescribed dose (amount of GH administered [mg] $\div$ amount of GH prescribed [mg]).

\section{Analyses}

Data analyses and calculations for adherence, GV and height standard deviation score (SDS) were performed by extracting the individual data from the SAIZEN-EDC system. Statistical analysis was performed using SAS-9.1 (SAS Institute, Cary, N.C., USA). Height SDS was calculated as (height - mean)/SD, where mean and SD were obtained from height reference ranges for Germany [17]. Only descriptive statistics were planned; any statistical testing was exploratory. Statistical analysis was performed using one-sided Student's t test and all calculated values were expressed as mean and SD unless stated otherwise.

In addition, data were evaluated in accordance with compliance as defined by Cutfield et al. [9]: good compliance, fewer than 1 missed dose per week (85.7-100\% proportion injected); medium compliance, 1-3 missed doses per week (57.1-85.7\% proportion injected), and poor compliance, more than 3 missed doses per week $(<57.1 \%$ proportion injected).

\section{Pubertal Status}

Clinical signs of puberty were collected to allow differentiation between prepubertal and pubertal children. Prepubertal was defined as absence of pubic hair development and testis volume less than $3 \mathrm{ml}$ for males, and absence of pubic hair and breast development for females. Pubertal males were defined as those with pubic hair development or testis volume more than $3 \mathrm{ml}$, and pubertal females were defined as those with pubic hair or breast development. 


\section{Results}

\section{Patients}

At the time of analysis, 1,365 patients were included in the registry, of whom 101 had clinical kit data available for evaluation. Data from 75 patients (46 male, $29 \mathrm{fe}$ male) were evaluated after excluding 26 data sets for reasons described earlier. Patients had a mean $( \pm$ SD) age of $12.5 \pm 3.5$ years and a mean height SDS of $-2.5 \pm 1.1$ at the start of the adherence monitoring period (table 1). Forty-eight patients were diagnosed with GHD, 18 with SGA, 6 with TS and 3 with CRF; 29 patients were prepubertal, 41 were pubertal and pubertal status was unavailable for the remaining 5 patients. The mean \pm SD prescribed somatotropin dose was $0.035 \pm 0.008 \mathrm{mg} / \mathrm{kg} / \mathrm{day}$ and the average observation time was $343 \pm 201$ days (range 28-1,034 days).

\section{Baseline GV and Height SDS}

Overall, mean ( $\pm \mathrm{SD}$ ) $\mathrm{GV}$ was $6.9 \pm 2.8 \mathrm{~cm} /$ year at the beginning of the adherence monitoring period (table 1). Boys had a higher GV than girls, and pubertal children had a higher GV than prepubertal children, but exploratory analyses showed no statistical differences in GV. GV was lowest in the TS and CRF groups $(4.2 \pm 3.2$ and $2.9 \pm 0.4 \mathrm{~cm} /$ year, respectively). Statistical analysis by diagnosis was not performed owing to small group numbers.

Female patients (height SDS $-2.9 \pm 1.1$ ) were significantly shorter than male patients $(-2.2 \pm 1.1$; $\mathrm{p}<0.026)$. Prepubertal children had a lower height SDS $(-2.7 \pm 1.0)$ than pubertal children $(-2.4 \pm 1.2)$, but the difference was not relevant (table 1). Patients with TS were more severely affected in terms of height SDS than were patients with other diagnoses.

\section{Adherence Rates}

Adherence data are summarized in table 2. The mean $( \pm \mathrm{SD}) \mathrm{rhGH}$ therapy adherence rate of all patients was $91.2 \pm 12.2 \%$. Adherence in males and females was similar $-90.5 \pm 13.1 \%$ and $92.2 \pm 10.7 \%$, respectively. Prepubertal children had the highest mean adherence rate of $96.5 \pm 3.9 \%$, which was significantly higher than the rate of $89.1 \pm 13.7 \%$ seen in pubertal children $(\mathrm{p}<0.005)$. However, median adherence rates of prepubertal $(97.4 \%)$ and pubertal patients (95.1\%) were similar.

There were no relevant differences in adherence rates with respect to diagnosis. The lowest rate was observed in the group of 6 patients with TS, with a low mean $(86.0 \pm$ $14.5 \%)$ and median (87.8\%) adherence rate.

Growth Hormone Treatment Adherence

in Prepubertal and Pubertal Children
Table 1. Auxological characteristics of children treated with growth hormone

\begin{tabular}{lrlll}
\hline & $\mathrm{n}$ & $\begin{array}{l}\text { Age, } \\
\text { years }\end{array}$ & $\begin{array}{l}\text { Height } \\
\text { SDS }\end{array}$ & $\begin{array}{l}\text { Growth velocity, } \\
\text { cm/year }\end{array}$ \\
\hline All & 75 & $12.5(3.5)$ & $-2.5(1.1)$ & $6.9(2.8)$ \\
$\quad$ Male & 46 & $13.3(3.3)$ & $-2.2(1.1)$ & $7.4(2.7)$ \\
$\quad$ Female & 29 & $11.3(3.5)$ & $-2.9(1.1)$ & $6.2(2.9)$ \\
$\quad$ Prepubertal & 29 & $10.0(3.4)$ & $-2.7(1.1)$ & $7.4(2.9)$ \\
$\quad$ Pubertal & 41 & $14.5(1.6)$ & $-2.4(1.2)$ & $6.8(2.6)$ \\
Diagnosis & & & & \\
$\quad$ GHD & 48 & $13.4(2.9)$ & $-2.2(1.1)$ & $7.3(2.5)$ \\
$\quad$ SGA & 18 & $11.0(4.0)$ & $-2.8(1.1)$ & $7.5(2.9)$ \\
$\quad$ TS & 6 & $11.3(4.8)$ & $-3.4(1.4)$ & $4.2(3.2)$ \\
CRF & 3 & $10.4(1.2)$ & $-2.9(0.0)$ & $2.9(0.4)$ \\
\hline
\end{tabular}

All values shown as mean (SD). Pubertal status was unavailable for 5 patients.

Table 2. Adherence of children with different growth disorders treated with growth hormone

\begin{tabular}{lrll}
\hline & $\mathrm{n}$ & Mean (SD), \% & Median, \% \\
\hline All & 75 & $91.2(12.2)$ & 96.0 \\
$\quad$ Male & 46 & $90.5(13.1)$ & 95.2 \\
$\quad$ Female & 29 & $92.2(10.7)$ & 96.4 \\
$\quad$ Prepubertal & 29 & $96.5(3.9)$ & 97.4 \\
$\quad \begin{array}{l}\text { Pubertal } \\
\text { Diagnosis }\end{array}$ & 41 & $89.1(13.7)$ & 95.1 \\
$\quad$ GHD & 48 & $91.4(11.0)$ & 95.5 \\
SGA & 18 & $91.1(15.3)$ & 96.0 \\
TS & 6 & $86.0(14.5)$ & 87.8 \\
$\quad$ CRF & 3 & $99.3(1.0)$ & 99.6 \\
\hline
\end{tabular}

Pubertal status was unavailable for 5 patients.

Post hoc intraindividual comparison of GV and adherence rate for prepubertal and pubertal children revealed no significant correlation (data not shown).

\section{Adherence Categories}

When analyzed categorically according to the definitions of Cutfield et al. [9], 2.7\% of all patients had poor compliance, $18.7 \%$ had medium compliance, and $78.7 \%$ had good compliance. Compliance was similar between boys and girls. Pubertal status revealed some differences, with $96.6 \%$ of prepubertal children categorized as good and the rest as medium compliers. Only $70.7 \%$ of pubertal children were good compliers (24.4\% medium, $4.9 \%$ 


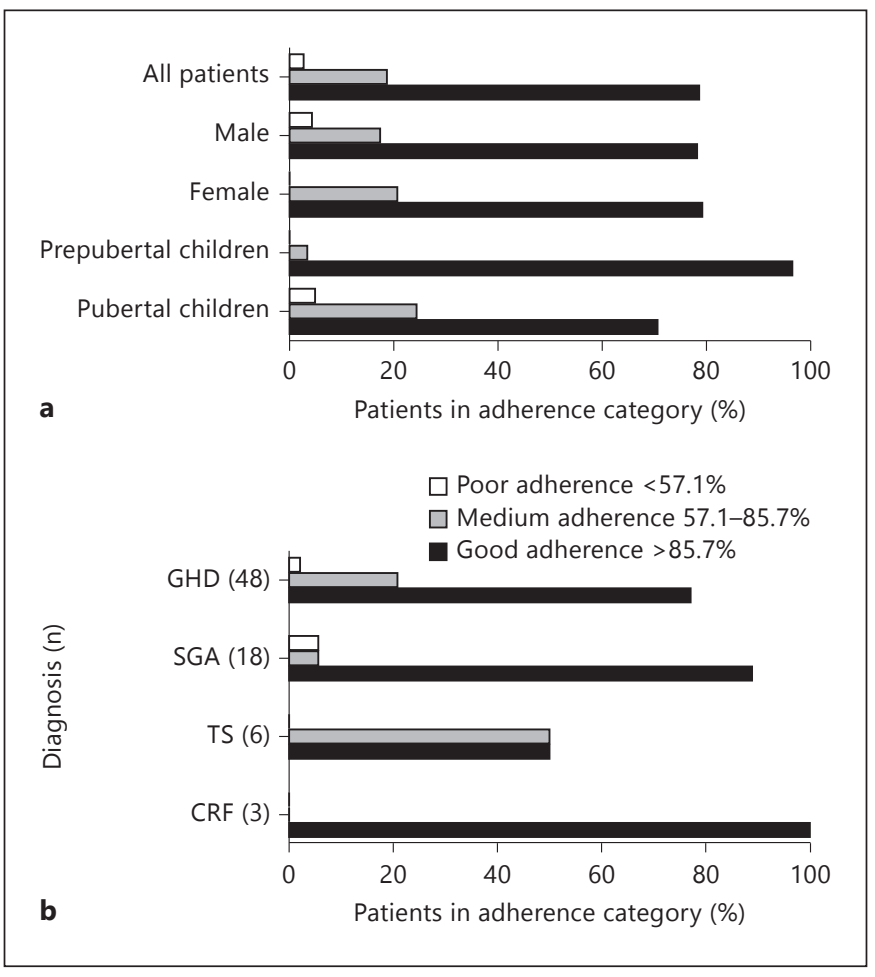

Fig. 1. Compliance rates (based on Cutfield et al. [9]) for children treated with growth hormone.

poor; fig. 1a). Children with GHD showed poor compliance (fig. 1 b), with only $77.1 \%$ of patients showing good compliance.

\section{Discussion}

The data presented here indicate that mean adherence in children treated with rhGH using the easypod device is good, with $91.2 \%$ of injections administered as prescribed. According to the compliance categories defined by Cutfield et al. [9], 78.7\% of the patients in our study showed good compliance and $21.4 \%$ were defined as having poor compliance.

Previous studies have described almost one quarter of rhGH-treated patients as missing more than two injections per week [11] or otherwise as noncompliant [18]. Cutfield et al. [9] described 66\% of all patients as noncompliant (i.e., missing one or more injection per week) over a 4-month study period. In addition, Kappelgaard and Laursen [19] reported in a recent review that up to $50 \%$ of children with TS and SGA were noncompliant with $\mathrm{GH}$ therapy. Part of the variation in reported compliance rates may be due to the method by which compliance is assessed. In the study by Cutfield et al. [9] there were large variations between subjective (parent-reported) and objective (empty vial count) compliance rates. Parent-reported noncompliance was $34 \%$ and returned vial count noncompliance showed $66 \%$ of patients as missing more than one dose per week. Similarly, a large-scale easypod user survey conducted over a 3-month period found that patient-reported compliance was higher than recorded compliance ( 90.2 vs. $87.5 \%$ ) [15], demonstrating the usefulness of a device to collect objective data.

It may be possible that the relatively high compliance rates seen in studies with the easypod device are at least partly driven by patients knowing that injection data can be monitored each time they visit the clinic, and can be easily compared with self-reported data.

Our results showed little effect of diagnosis on adherence in patients with GHD or SGA. Lower adherence was detected in patients with TS, but it should be noted that there were only 6 patients in this group. In contrast, pubertal children showed significantly reduced adherence to rhGH therapy compared with prepubertal children $(\mathrm{p}<0.005)$. This is not an uncommon observation $[10$, $18]$.

Poor adherence may be a result of poor education, psychological and emotional problems, social problems or technical handling issues of the drug delivery device [20]. According to the retrospective survey of Rosenfeld and Bakker [18], noncompliance was associated with misconceptions about consequences of missed doses, discomfort with injections, dissatisfaction with results, and inadequate contact with healthcare professionals.

Compliance rates with self-administered injectable therapies in diseases such as diabetes and multiple sclerosis are typically about $60-70 \%[21,22]$. The adherence rates measured in this study (91.2\%) and in another larger study using the easypod device (87.5\%) [15] are higher, as are adherence rates among patients with multiple sclerosis using the similar RebiSmart ${ }^{\mathrm{TM}}$ device [23]. This may be because the patient knows that his/her injection history can be monitored accurately. The reproducibility of injection depth and duration with an autoinjector device is another important factor in treatment adherence, in that the patient can be confident that the full dose has been administered correctly on every occasion [24] rather than suffering from incomplete dosing (and therefore reduced adherence with the prescribed dose) through poor injection technique. In their report in 2003 [25], the World Health Organization called for strategies to improve adherence, stating that health systems and provid- 
ers need to develop means of accurately assessing not only adherence, but also those factors that influence it. As a result of our own findings of poor adherence in pubertal patients and the factors discussed above, we propose that stronger support for adolescents (and their families) who may have been receiving rhGH therapy for several years may help to improve compliance. Early identification of poor adherence and interventions to reinforce patient and carer understanding of the importance of rhGH therapy are essential [26]. To this end, availability of reliable adherence data to the clinical team would be helpful.

Our study was limited by a relatively small sample and wide variation in the size of the diagnostic groups; as a result, the generalizability of our findings is limited. The OS Saizen-online long-term study offers an opportunity to perform a deeper analysis of the critical points that may affect treatment adherence. We suggest that a more detailed and ongoing analysis of the easypod adherence data in terms of diagnosis and pubertal status may improve understanding of the factors affecting patient adherence with rhGH therapy.

\section{Acknowledgments}

The study was sponsored by Merck Serono GmbH Germany, an affiliate of Merck KGaA, Darmstadt, Germany. Editorial support in the form of writing and collating author comments was provided by Jackie Marchington, $\mathrm{PhD}$ (Caudex Medical, Oxford, UK), and funded by Merck Serono GmbH.

\section{Disclosure Statement}

J.B,. J.I., K.P.U., R.S., E.M.R., and B.H. have nothing to disclose. E.S. has received honoraria or consultation fees from Bayer, Eli Lilly, Ferring, Ipsen, Pfizer, Merck Serono, NovoNordisk; R.R. is an employee of Merck Serono GmbH; K.P.H. has received financial support for this study and others from Merck Serono $\mathrm{GmbH}$.

\section{References}

1 Ross J, Czernichow P, Biller BM, Colao A, Reiter E, Kiess W: Growth hormone: health considerations beyond height gain. Pediatrics 2010;125:e906-e918.

2 Raben MS: Treatment of a pituitary dwarf with human growth hormone. J Clin Endocrinol Metab 1958;18:901-903.

- Flodh H: Human growth hormone produced with recombinant DNA technology: development and production. Acta Paediatr Scand Suppl 1986;325:1-9.

4 Zeisel HJ, von Petrykowski W, Wais U: Pharmacokinetics and short-term metabolic effects of mammalian cell-derived biosynthetic human growth hormone in man. Horm Res 1992;37(suppl 2):5-13.

5 Richmond E, Rogol AD: Current indications for growth hormone therapy for children and adolescents. Endocr Dev 2010;18:92-108.

6 Cole TJ, Hindmarsh PC, Dunger DB: Growth hormone $(\mathrm{GH})$ provocation tests and the response to GH treatment in GH deficiency. Arch Dis Child 2004;89:1024-1027.

7 Cutfield W, Lindberg A, Albertsson Wikland K, Chatelain P, Ranke MB, Wilton P: Final height in idiopathic growth hormone deficiency: the KIGS experience. KIGS International Board. Acta Paediatr Suppl 1999;88: 72-75.

8 Lanes R: Long-term outcome of growth hormone therapy in children and adolescents. Treat Endocrinol 2004;3:53-66.

>9 Cutfield WS, Derraik JG, Gunn AJ, Reid K, Delany T, Robinson E, Hofman PL: Noncompliance with growth hormone treatment in children is common and impairs linear growth. PLoS One 2011;6:e16223.
Haverkamp F, Johansson L, Dumas H, Langham S, Tauber M, Veimo D, Chiarelli F: Observations of nonadherence to recombinant human growth hormone therapy in clinical practice. Clin Ther 2008;30:307-316.

11 Kapoor RR, Burke SA, Sparrow SE, Hughes IA, Dunger DB, Ong KK, Acerini CL: Monitoring of concordance in growth hormone therapy. Arch Dis Child 2008;93:147-148.

12 Lustig RH: Optimizing growth hormone efficacy: an evidence-based analysis. Horm Res 2004;62(suppl 3):93-97.

13 Dahlgren J, Veimo D, Johansson L, Bech I: Patient acceptance of a novel electronic auto-injector device to administer recombinant human growth hormone: results from an openlabel, user survey of everyday use. Curr Med Res Opin 2007;23:1649-1655.

14 Dahlgren J: Easypod: a new electronic injection device for growth hormone. Expert Rev Med Devices 2008;5:297-304.

15 Bozzola M, Colle M, Halldin-Stenlid M, Larroque S, Zignani M: Treatment adherence with the easypod growth hormone electronic auto-injector and patient acceptance: survey results from 824 children and their parents. BMC Endocr Disord 2011;11:4.

16 Bundesinstitut für Arnzeimittel und Medizinprodukte. http://www.bfarm.de/EN/BfArM/ BfArMService/AMG_en/amg-node-en.html, 2006.

17 Kruse K: Pädiatrische Endokrinologie. Stuttgart, Georg Thieme Verlag, 1999.

18 Rosenfeld RG, Bakker B: Compliance and persistence in pediatric and adult patients receiving growth hormone therapy. Endocr Pract 2008;14:143-154.
9 Kappelgaard AM, Laursen T: The benefits of growth hormone therapy in patients with Turner syndrome, Noonan syndrome and children born small for gestational age. Growth Horm IGF Res 2011;21:305-313.

20 Haverkamp F, Gasteyger C: A review of biopsychosocial strategies to prevent and overcome early-recognized poor adherence in growth hormone therapy of children. J Med Econ 2011;14:448-457.

21 Costello K, Kennedy P, Scanzillo J: Recognizing nonadherence in patients with multiple sclerosis and maintaining treatment adherence in the long term. Medscape J Med 2008;10:225.

22 Cramer JA: A systematic review of adherence with medications for diabetes. Diabetes Care 2004;27:1218-1224.

-23 Lugaresi A, Florio C, Brescia-Morra V, Cottone S, Bellantonio P, Clerico M, Centonze D, Uccelli A, di Ioia M, De Luca G, Marcellusi A, Paolillo A: Patient adherence to and tolerability of self-administered interferon beta-1a using an electronic autoinjection device: a multicentre, open-label, phase IV study. BMC Neurol 2012;12:7.

24 Stanhope R, Albanese A, Moyle L, Hamill G: Optimum method for administration of biosynthetic human growth hormone: a randomised crossover trial of an Auto Injector and a pen injection system. Arch Dis Child 1992;67:994-997.

25 Adherence to Long-Term Therapies: Evidence for Action. Geneva, World Health Organization, 2003.

26 Norgren S: Adherence remains a challenge for patients receiving growth hormone therapy. $\mathrm{Pe}$ diatr Endocrinol Rev 2009;6(suppl 4):545-548.
Growth Hormone Treatment Adherence in Prepubertal and Pubertal Children 